\title{
Genetic incorporation of the protein transduction domain of Tat into Ad5 fiber enhances gene transfer efficacy Tie Han ${ }^{\dagger 1}$, Yizhe Tang ${ }^{\dagger 1}$, Hideyo Ugai ${ }^{1}$, Leslie E Perry ${ }^{1}$, Gene P Siegal2,4, Juan L Contreras ${ }^{3}$ and Hongju Wu*1,5,6
}

\begin{abstract}
Address: ${ }^{1}$ Division of Human Gene Therapy, Department of Medicine, University of Alabama at Birmingham, Birmingham, USA, ${ }^{2}$ Division of Human Gene Therapy, Departments of Pathology, University of Alabama at Birmingham, Birmingham, USA, ${ }^{3}$ Division of Human Gene Therapy, Departments of Surgery, University of Alabama at Birmingham, Birmingham, USA, ${ }^{4}$ Division of Human Gene Therapy, Departments of Cell Biology, University of Alabama at Birmingham, Birmingham, USA, ${ }^{5}$ Division of Human Gene Therapy, Departments of Obstetrics and Gynecology, University of Alabama at Birmingham, Birmingham, USA and ${ }^{6}$ Gene Therapy Center, University of Alabama at Birmingham, Birmingham, USA
\end{abstract}

Email: Tie Han - than@uab.edu; Yizhe Tang - tyzhet@uab.edu; Hideyo Ugai - hugai@uab.edu; Leslie E Perry - perrylpl@uab.edu; Gene P Siegal - gsiegal@uab.edu; Juan L Contreras - jcontrer@uab.edu; Hongju Wu* - hongjuwu@uab.edu

* Corresponding author †Equal contributors

Published: 24 October 2007

Virology Journal 2007, 4:103 doi:10.1186/1743-422X-4-103

This article is available from: http://www.virologyj.com/content/4/I/I03

(C) 2007 Han et al; licensee BioMed Central Ltd.

This is an Open Access article distributed under the terms of the Creative Commons Attribution License (http://creativecommons.org/licenses/by/2.0), which permits unrestricted use, distribution, and reproduction in any medium, provided the original work is properly cited.

Received: 22 August 2007

Accepted: 24 October 2007

\begin{abstract}
Background: Human adenovirus serotype 5 (Ad5) has been widely explored as a gene delivery vector for a variety of diseases. Many target cells, however, express low levels of Ad5 native receptor, the Coxsackie-Adenovirus Receptor (CAR), and thus are resistant to Ad5 infection. The Protein Transduction Domain of the HIV Tat protein, namely PTD ${ }_{\text {tat }}$, has been shown to mediate protein transduction in a wide range of cells. We hypothesize that re-targeting Ad5 vector via the PTD $_{\text {tat }}$ motif would improve the efficacy of Ad5-mediated gene delivery.

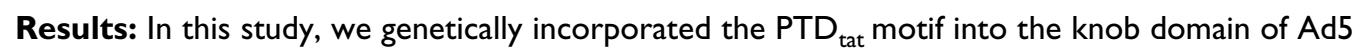

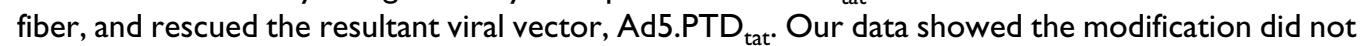
interfere with Ad5 binding to its native receptor CAR, suggesting Ad5 infection via the CAR pathway is retained. In addition, we found that Ad5.PTD ${ }_{\text {tat }}$ exhibited enhanced gene transfer efficacy in all of the cell lines that we have tested, which included both low-CAR and high-CAR decorated cells. Competitive inhibition assays suggested the enhanced infectivity of Ad5.PTD tat was mediated by binding of the positively charged PTD ${ }_{\text {tat }}$ peptide to the negatively charged epitopes on the cells' surface. Furthermore, we investigated in vivo gene delivery efficacy of Ad5.PTD tat using subcutaneous tumor models established with UII8MG glioma cells, and found that Ad5.PTD tat exhibited enhanced gene transfer efficacy compared to unmodified Ad5 vector as analyzed by a non-invasive fluorescence imaging technique.

Conclusion: Genetic incorporation of the PTD ${ }_{\text {tat }}$ motif into Ad5 fiber allowed Ad5 vectors to infect cells via an alternative PTD $_{\text {tat }}$ targeting motif while retaining the native CAR-mediated infection pathway. The enhanced infectivity was demonstrated in both cultured cells and in in vivo tumor models. Taken together, our study identifies a novel tropism expanded Ad5 vector that may be useful for clinical gene therapy applications.
\end{abstract}




\section{Background}

Human adenovirus serotype 5 (Ad5) has been widely exploited as a gene delivery vector, owing largely to its superior gene delivery efficacy, minor pathological effect on humans, and easy manipulation in vitro. Several problems, however, have been identified in the course of development and application of Ad5-based gene therapy protocols, one of which is the inefficient gene delivery into target cells [1-3]. It is known that infection of Ad5 is initiated by attachment of its capsid fiber protein to the cell surface coxsackievirus adenovirus receptor (CAR), which is followed by interaction of its penton base with $\alpha_{\mathrm{v}}$ integrins that triggers the internalization of the viruses [47]. Many target cells, such as malignant tumor cells, are found to express very low level of CAR, and thus are resistant to Ad5 infection. Therefore, strategies to re-direct Ad5 infection via alternative receptors would be useful for gene therapy applications.

Since fiber, the capsid protein extruding from the Ad virion surface, is an essential mediator of Ad5 infection, fiber modification has been explored as a means to re-direct Ad5 tropism [1]. Ad5 fiber is composed of an N-terminal tail that is attached to a penton base on the virion surface, a shaft domain consisting of 22 repeats of a 15-amino acid residue motif, and a C-terminal globular domain, named knob, which functions as a receptor binding domain. Because of the essential role of the fiber knob domain in mediating Ad5 infection, knob modification could be one of the most effective ways to re-direct Ad5 tropism. Indeed, both genetic and non-genetic strategies have been shown to successfully retarget Ad5 vectors. For example, bi-specific adapter proteins that bind both the knob domain and an alternative receptor expressed on the surface of the target cells have been employed to re-direct Ad5 infection [8-11]. In addition, genetic incorporation of RGD peptide and/or a polylysine epitope into the knob domain allowed Ad5 to infect cells through alternative receptors (cell surface integrins for RGD and negatively charged epitopes such as heparan sulfate proteoglycans for polylysine), thus greatly improving the gene delivery efficacy Ad5 vectors in many target cells [12-15].

Protein transduction domains (PTD) or Cell Penetrating Peptides (CPP) are a class of small peptides that can traverse the plasma membrane of many, if not all, mammalian cells [16-20]. Among these peptides, the PTD of the Tat protein $\left(\mathrm{PTD}_{\mathrm{tat}}\right)$ of human immunodeficiency viruses types 1 and 2 (HIV-1 and HIV-2) has been one of the most widely studied PTDs. PTD ${ }_{\text {tat }}$ consists of 11 highly basic amino acid residues, YGRKKRRQRRR [21,22]. The mechanism of how $\mathrm{PTD}_{\text {tat }}$ crosses the cell membrane has been intensively studied, but controversies remain [2326]. Nonetheless, it is commonly agreed upon that the interaction between the positive charge of the PTD domain and the negative epitopes, in particular, the heparan sulfate proteoglycans expressed on cell membranes, plays an essential role in the internalization of PTD $_{\text {tat }}$ fusion proteins $[17,20,27]$. Further studies suggest that the interaction between $\mathrm{PTD}_{\text {tat }}$ and heparan sulfate is specified by both charge and structure of the peptide and the proteoglycans $[17,27-30]$.

Given the potential importance of the PTDs in drug delivery, much interest has been generated in exploiting this system as a tool to deliver therapeutic molecules or particles into mammalian cells. PTDs have already been widely used in the field of protein therapy whereby PTDs are fused to the protein of interest, and used to deliver the heterologous protein into cultured cells [17,20,31]. Interestingly, it has been demonstrated in several mouse studies that PTD $_{\text {tat }}$ fusion proteins can be delivered into different tissues in vivo following systemic administration, and therapeutic benefits have been observed [32-35]. In addition, PTDs have been used to deliver other large molecules or particles including plasmids, liposomes, nanoparticles, phages and viruses, with variable efficiency [36-41]. In these applications, PTDs were conjugated to the vehicle of interest by incubation in coupling solutions. In other words, the coating of the vehicle was not based on genetic modification, but on ionic or other interactions between the peptides and the vehicle.

Because of the potency of $\mathrm{PTD}_{\text {tat }}$ in mediating cellular uptake of small and large molecules, in this study, we attempted to re-direct Ad5 infection via the PTD ${ }_{\text {tat }}$ pathway. Previous studies have demonstrated pre-treatment of Ad particles with chemically synthesized PTDs or bi-specific adaptor proteins composed of the extracellular domain of CAR and PTDs improved Ad infection [37,42]. Nonetheless, intrinsic to these non-genetic modification strategies, the efficiency of retargeting depended on the affinity and stability of protein-protein interactions, and thus may be highly variable in different systems. In addition, a large amount of peptide or adaptor protein is seen to be required for in vivo investigations. Our study was designed to retarget Ad5 vectors to the PTD $\mathrm{Pat}_{\text {tathway }}$ using a genetic capsid modification strategy. We genetically incorporated the sequences encoding the PTD $\mathrm{Pta}_{\text {tat }}$ peptide into the 3' end of the Ad5 fiber gene, rescued the modified viruses, and characterized them in detail. Our data demonstrated that genetic modification of Ad5 fiber with the PTD $\mathrm{Dta}_{\text {th }}$ motif greatly improved the efficacy of gene delivery in both cultured cells and in tumor models. Our study thus identified a novel tropism expanded Ad5 vector that may be useful for clinical gene therapy applications, especially for applications involving gene delivery into low-CAR expressing cells. 


\section{Results}

Development of PTD tat $^{- \text {modified Ad5 vector - Ad5.PTD }}$ tat As the receptor binding domain, the knob of the Ad5 fiber has been shown to be an effective site for incorporating foreign targeting motifs [12-15]. In this study, we genetically incorporated the PTD $_{\text {tat }}$ epitope into the C-terminal end of the fiber knob domain (Fig. 1). The Ad5 genome contains about 36 kilobases $(\mathrm{kb})$ and is too large for direct modification using conventional cloning techniques. To achieve our goal, we therefore established a bacteria-based homologous recombination system for Ad5 fiber modification [15]. Using this system, the nucleotide sequences encoding PTD ${ }_{\text {tat }}$ were incorporated into the 3 'end of the fiber gene, immediately before the stop code. The modified Ad5 (Ad5.PTD ${ }_{\text {tat }}$ ) and the unmodified control (Ad5) were both replication deficient as their E1 region, which is essential for Ad5 replication, was replaced with a CMV promoter-driven green fluorescence protein (GFP) reporter gene. The viruses were rescued in 293 cells stably expressing Ad-E1 genes, and purified with $\mathrm{CsCl}$ gradient ultracentrifugation. The yield of Ad5.PTD ${ }_{\text {tat }}$ total viral particles (VPs) and the ratio of VPs : plaque formation units (pfu) were in the same range as that of unmodified Ad5 viruses, suggesting that the modification did not interfere with virus formation (data not shown). The modification was confirmed by both polymerase chain reaction (PCR) and sequence analysis of the modified region of the viral genome using viral DNA from purified Ad5 and Ad5.PTDtat viruses (data not shown).

A

\section{PTD $_{\text {tat }}$ peptide ( $($ ): YGRKKRRQRRR}

B

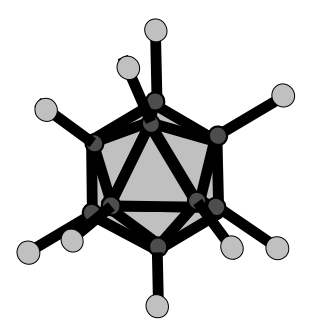

Ad5

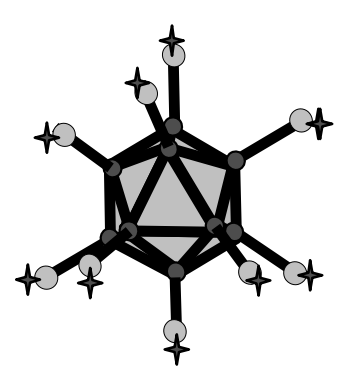

Ad5.PTD $_{\text {tat }}$

\section{Figure I}

Diagram of PTD $_{\text {tat }}$ modified Ad5 vector. (A) PTD tat peptide incorporated into the fiber knob domain. (B) Structural diagram of Ad5 and Ad5.PTD tat vector. The PTD ${ }_{\text {tat }}$ motif was incorporated at the C-terminal end of the fiber.

\section{CAR-binding activity of Ad5.PTD ${ }_{\text {tat }}$}

Unmodified Ad5 viruses interact with their native receptor CAR via the fiber knob domain. We thus examined whether incorporation of $\mathrm{PTD}_{\text {tat }}$ into the knob domain interfered with the Ad5-CAR interaction. An enzymelinked immunosorbent assay (ELISA) was employed in this regard. In the assay, Ad5.PTD ${ }_{\text {tat }}$ or Ad5 viral particles were immobilized in the wells of a 96-well maxi-sorp plate, and incubated with varying amounts of recombinant extracellular domain of CAR (sCAR) protein. After extensive washing, binding of sCAR to the viruses were assessed with an anti-CAR antibody and corresponding secondary antibody conjugated to alkaline phosphatase (AP). The OD405 readings resulting from the color reaction with an AP substrate correspond to the binding activity of sCAR to the viruses. As shown in Fig. 2, binding of sCAR to Ad5.PTD ${ }_{\text {tat }}$ is similar to that of unmodified Ad5, suggesting the genetically modified vector Ad5.PTD tat maintained its ability to interact with the Ad5 native receptor, CAR.

\section{Cell-binding activities of Ad5.PTD}

The fiber knob domain of Ad is responsible for Ad5 binding to its target cells, which is the initial step in viral infection. Ad5.PTD ${ }_{\text {tat }}$ was designed to re-direct Ad5 infection.

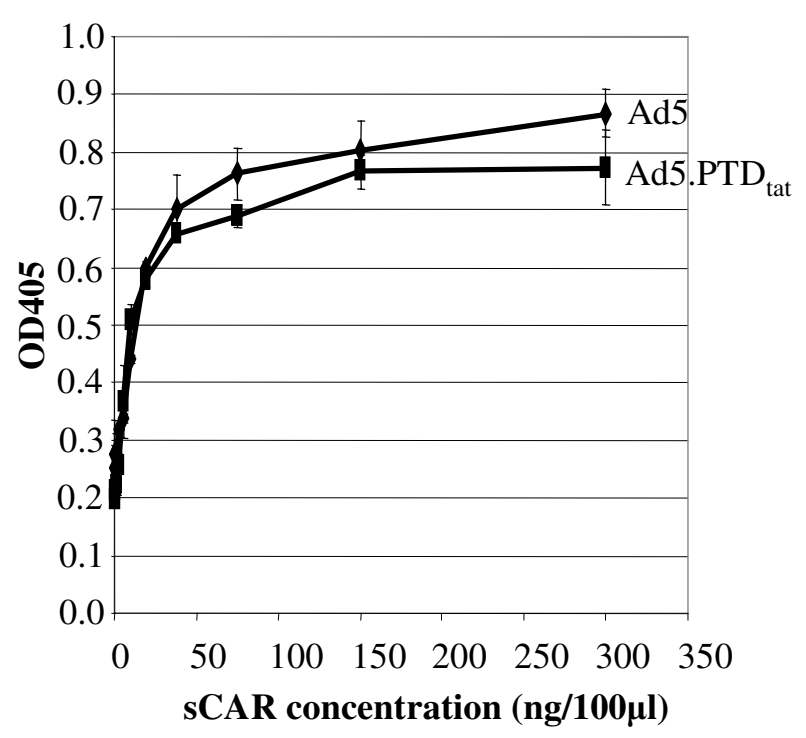

Figure 2

Ad5.PTD tat $_{\text {showed similar CAR-binding activity to }}$ unmodified Ad5 vector in an ELISA-based binding assay. In the experiment, $10^{9} \mathrm{VPs}$ of each viral vector were immobilized in the wells of a 96-well ELISA plate, and incubated with increasing concentrations of recombinant SCAR (extracellular domain of CAR, i.e. soluble CAR). The binding activity was detected by AP activity conjugated to detection antibodies. 
We thus examined whether PTD ${ }_{\text {tat }}$ modification had any effect on Ad5 binding to cells. To distinguish viruses bound to cells from viruses internalized into the cells, we performed a cell binding assay at $4{ }^{\circ} \mathrm{C}$ since Ad internalization occurs through receptor-mediated endocytosis which is energy dependent, and is thus inhibited at $4{ }^{\circ} \mathrm{C}$ $[5,7]$. In the assay, Ad5.PTD ${ }_{\text {tat }}$ or control Ad5 was incubated with cells expressing different levels of CAR at $4{ }^{\circ} \mathrm{C}$ for 1 hour, and the bound viral particles were examined by a quantitative PCR assay which assessed the viral genome copies in the cell lysates. We found that Ad5.PTDtat exhibited a significant higher cell-binding activity in almost all of the cells we examined, including both highCAR and low-CAR containing cells. Shown in Fig. 3 are results obtained in two representative cell lines: high-CAR expressing Hela cells, and low-CAR expressing U118MG cells $[43,44]$.

\section{Enhanced gene transfer efficacy of Ad5.PTD}

We further investigated the gene transfer efficacy of Ad5.PTD ${ }_{\text {tat }}$ in a variety of cultured cells using the reporter GFP protein. Ad5.PTD ${ }_{\text {tat }}$ vector or unmodified Ad5 was used to infect cells at different multiplicities of infection (MOIs). Two days after infection, we evaluated the transgene expression using a fluorescent microscope and a fluorescent plate reader. We found that Ad5.PTD tat showed more efficient gene delivery than unmodified Ad5 in all of the cells tested (Fig. 4). In particular, Ad5.PTD tat exhibited significantly higher gene transfer efficacy than unmodified Ad5 in the cells expressing low or medium levels of CAR such as RD cells, U118MG cells, and D65MG cells $[43,44]$. In high-CAR expressing cells that are readily accessible to unmodified Ad5 vector, Ad5.PTD ${ }_{\text {tat }}$ also showed enhanced infectivity, presumably because Ad5.PTD ${ }_{\text {tat }}$ maintained the CAR-mediated infection pathway while gaining extra targeting activity through the PTD $_{\text {tat }}$ pathway (Fig. 4).

Identification of pathways mediating Ad5.PTD tat $_{\text {infection }}$ Ad5.PTD ${ }_{\text {tat }}$ showed enhanced gene delivery efficacy compared to unmodified Ad5 vectors. To confirm that this expanded tropism was mediated by the genetically incorporated targeting motif $\mathrm{PTD}_{\mathrm{tat}}$, we performed a gene transfer assay in the presence of competitive inhibitors. It has been shown that the interaction between the positively charged $\mathrm{PTD}_{\text {tat }}$ and the negatively charged cell surface epitopes such as heparan sulfate proteoglycans is essential for PTD $_{\text {tat }}$ mediated protein transduction. Heparin, the structural analogue of heparan sulfate, would thus be expected to inhibit PTD $_{\text {tat }}$ mediated infection. In addition, recombinant knob protein was used to block the native CAR-mediated Ad5 infection because it compete with Ad5 vectors for cell surface CAR. In low-CAR containing U118MG cells [44], due to the paucity of CAR, unmodified Ad5 showed poor gene transfer efficacy, and neither
A

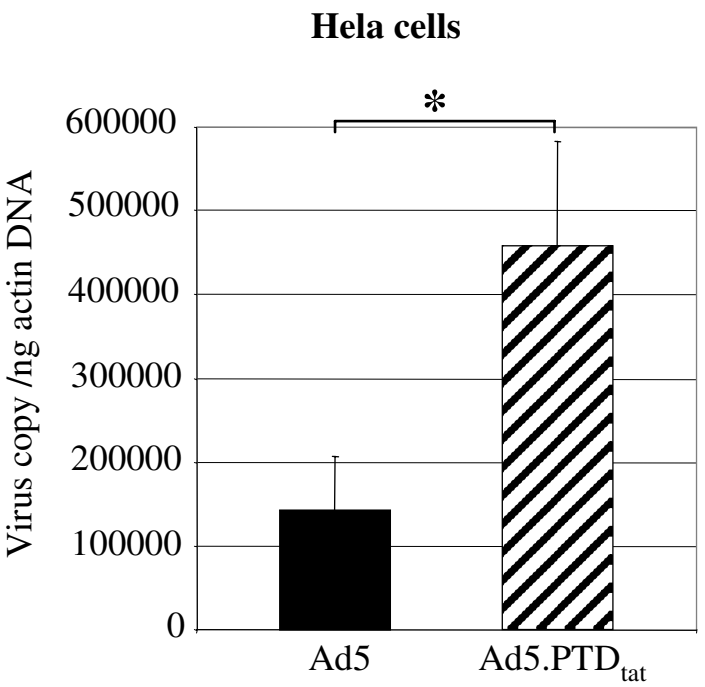

B

\section{U118MG cells}

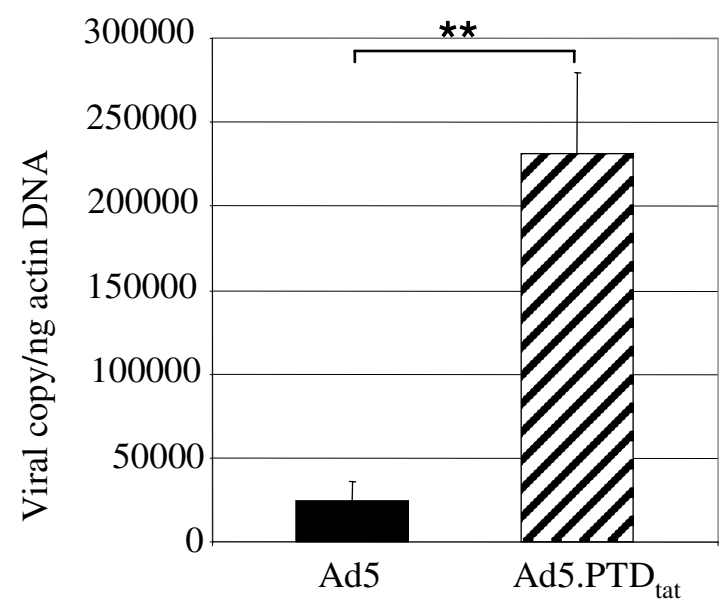

Figure 3

PTD ${ }_{\text {tat }}$ modification promoted Ad5 binding to cell surfaces. Binding of Ad5 and Ad5.PTD ${ }_{\text {tat }}$ were examined in both high-CAR expressing Hela cells $(A)$ and low-CAR expressing UI I8MG cells (B) at $4^{\circ} \mathrm{C}$. The amount of viruses associated with the cells was determined by quantitative PCR after DNA isolation from the cell lysate, and the viral copy numbers were normalized to actin DNA in the samples. The $*$ indicates $p<0.05$ and $* *$ indicates $p<0.01$ as analyzed by the Student's t-test.

knob nor heparin had any effect on Ad5-mediated transgene expression (Fig. 5A). In contrast, Ad5.PTD ${ }_{\text {tat }}$ exhibited efficient gene delivery into U118MG cells, which was completely inhibited by heparin, but not by the recombinant knob protein (Fig. 5A). These data demonstrated 
A

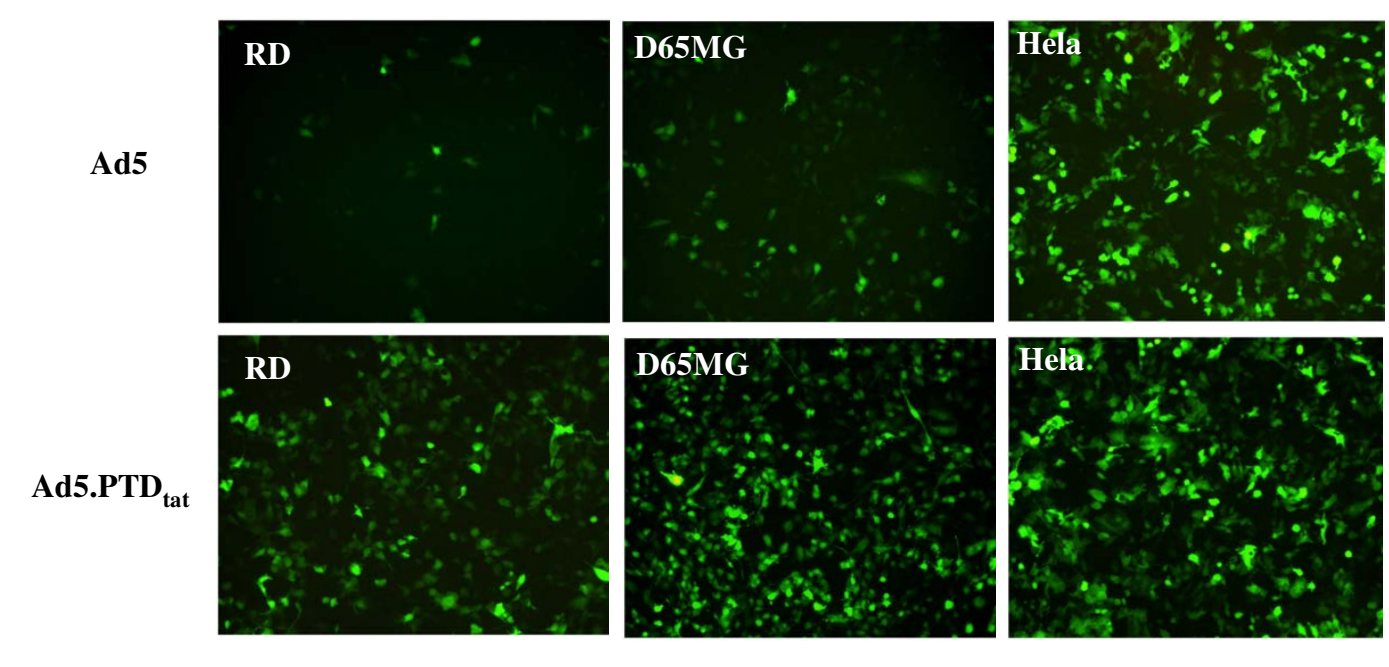

B
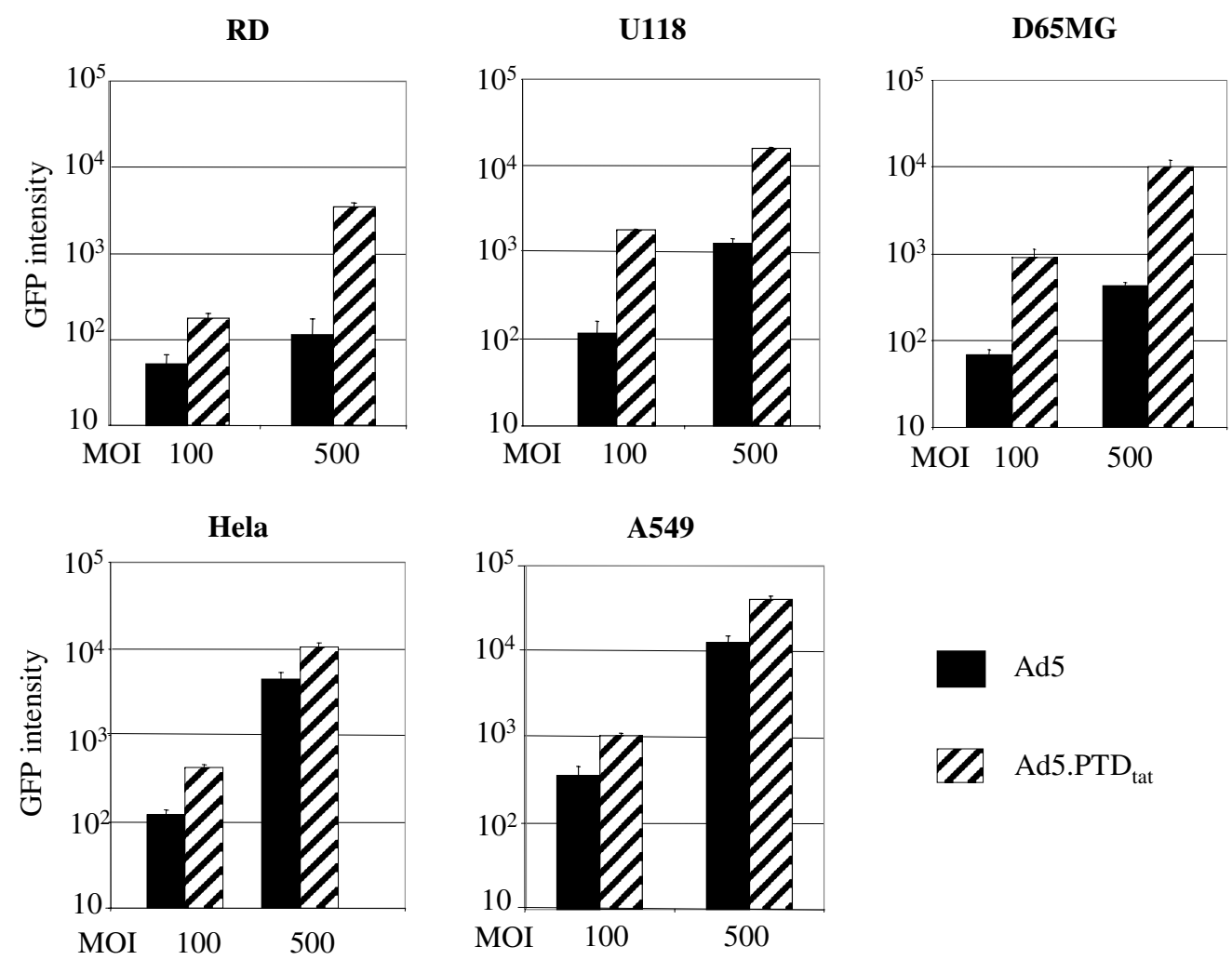

\section{Figure 4}

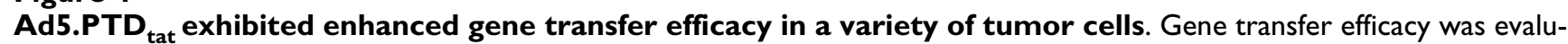
ated by use of a GFP reporter that was carried in the EI region of each vector. In the assay, tumor cells expressing varying levels of CAR were infected with either Ad5 or Ad5.PTD tat at an MOI of 100 or $500 \mathrm{VPs} /$ cell, and GFP expression was examined by fluorescence microscopy and a fluorescence plate reader. (A) Representative fluorescence images of low-CAR containing cells (RD), medium-CAR containing cells (D65MG) and high-CAR expressing cells (Hela) that were infected with Ad5 or Ad5.PTD ${ }_{\text {tat }}$ at an MOI of 500 VPs/cell. (B) GFP expression in a variety of cells infected with either Ad5 or Ad5.PTD ${ }_{\text {tat }}$ was quantified using a fluorescence plate reader. 
Ad5.PTD ${ }_{\text {tat }}$ infected low-CAR expressing cells mainly through the incorporated PTD $_{\text {tat }}$ motif. In high-CAR containing A549 cells [43], infection of unmodified Ad5 was completely blocked by recombinant knob protein while heparin had little effect, confirming that unmodified Ad5 mainly infected cells through the CAR pathway (Fig. 5B).

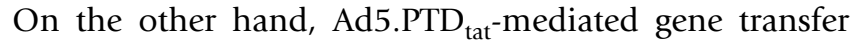
was partially blocked by either knob or heparin, but completely blocked in the presence of both knob and heparin, suggesting Ad5.PTD ${ }_{\text {tat }}$ could infect cells via both CAR and

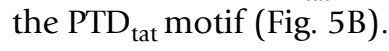

In vivo gene transfer efficacy of Ad5.PTD

We next examined whether the infectivity-enhanced vector Ad5.PTD ${ }_{\text {tat }}$ could deliver enhanced gene transfer efficacy in vivo. Since Ad5.PTD tat $_{\text {showed more profound }}$ infectivity enhancement for low-CAR expressing tumor cells in vitro, we assessed the in vivo gene delivery efficacy of the Ad5 vectors using tumor models established with low-CAR containing U118MG cells. After the tumors were established subcutaneously in athymic (nude) mice, PBS, unmodified Ad5, or Ad5.PTD ${ }_{\text {tat }}$ vectors were injected into the tumors. The gene delivery efficacy of each vector was analyzed by non-invasive fluorescence imaging that detected GFP expression in live mice. As shown in Fig. 6A,
A
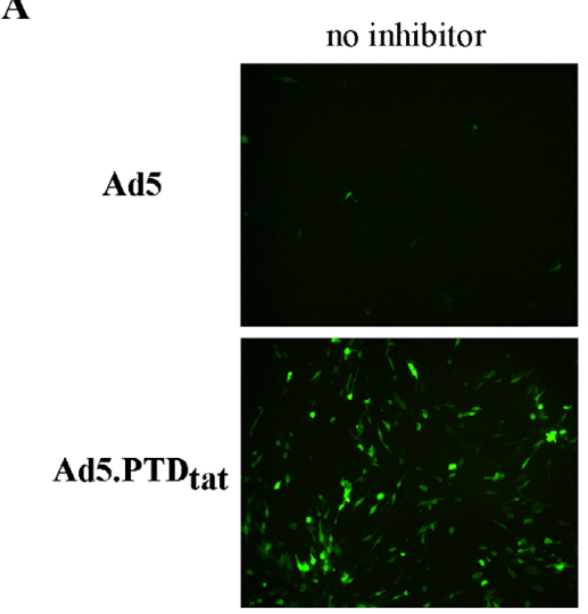

B

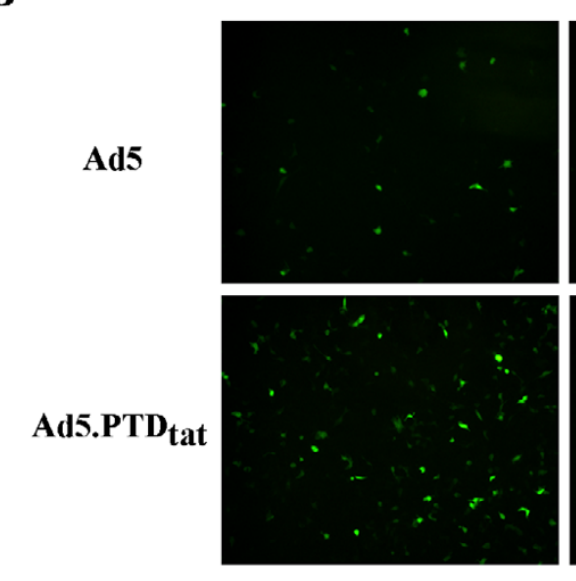

$+\mathrm{knob}$
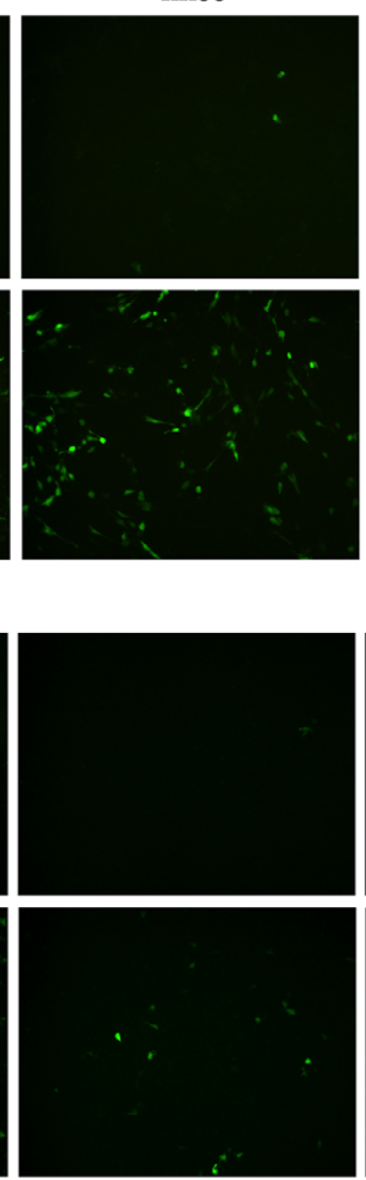

+ heparin
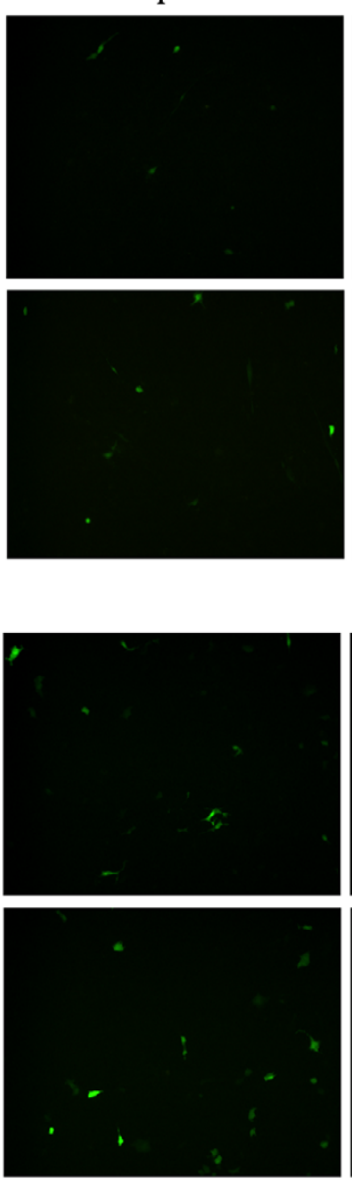

+ knob +heparin

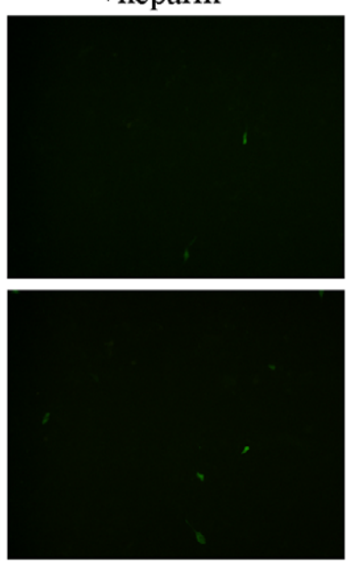

\section{Figure 5}

Competitive inhibition assay showing the enhanced gene transfer efficacy of Ad5.PTD tat $_{\text {was }}$ mediated by the PTD $_{\text {tat }}$ motif. In this assay, recombinant knob protein $(50 \mu \mathrm{g} / \mathrm{ml})$ was used to block CAR-mediated viral infection, and heparin

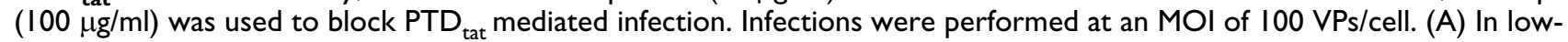

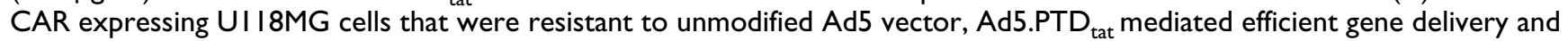
the efficacy was completely inhibited by heparin, while recombinant knob had little effect, suggesting the enhanced infectivity of Ad5.PTD tat $_{\text {in low-CAR expressing cells resulted from the PTD tat }}$ motif. (B) In high-CAR expressing A549 cells, Ad5.PTD mediated gene delivery was partially inhibited with either knob or heparin, while being completely inhibited in the presence of

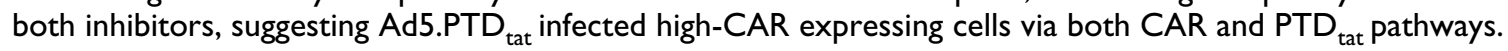


Ad5.PTD ${ }_{\text {tat }}$-infected tumors showed more intensive green fluorescence signals than Ad5-infected tumors, while no signal was detected in PBS-injected tumors. Quantitative analysis of the green fluorescence signals revealed that Ad5.PTD ${ }_{\text {tat }}$-mediated GFP expression was significantly higher than that of unmodified Ad5 vector in the tumors $(p<0.01)$ (Fig. 6B). These data suggest the infectivity-

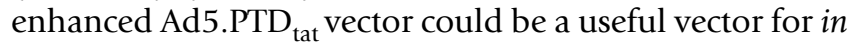
vivo gene delivery into tumors, which is essential for cancer gene therapy.

\section{Discussion}

In this study, we sought to improve the gene transfer efficacy of Ad 5 vectors by genetic modification of the fiber knob domain with a PTD ${ }_{\text {tat }}$ motif. Our data demonstrated the success of this strategy. The fiber modified Ad5 vector,
Ad5.PTD ${ }_{\text {tat }^{\prime}}$ not only exhibited enhanced gene delivery efficiency of Ad5 vectors in low-CAR cells that are resistant to unmodified Ad5 infection, but also in high-CAR cells that are permissive to Ad5 infection. The enhanced infectivity of Ad5.PTD $\mathrm{tat}$ was found to be mediated by targeting of PTD $_{\text {tat }}$ to the negatively charged epitopes such as heparan sulfate containing proteoglycans on cell surface. In addition, we found PTD ${ }_{\text {tat }}$ mediated Ad5.PTD tat infection is additive to native CAR-mediated infection as assessed by competitive inhibition assays, which was not

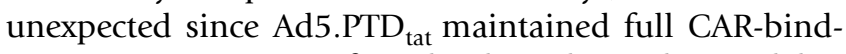
ing activity. More significantly, the enhanced gene delivery efficacy of Ad5.PTD ${ }_{\text {tat }}$ was demonstrated in vivo using low-CAR U118MG tumor models, and employment of a recently developed non-invasive optical imaging system

A
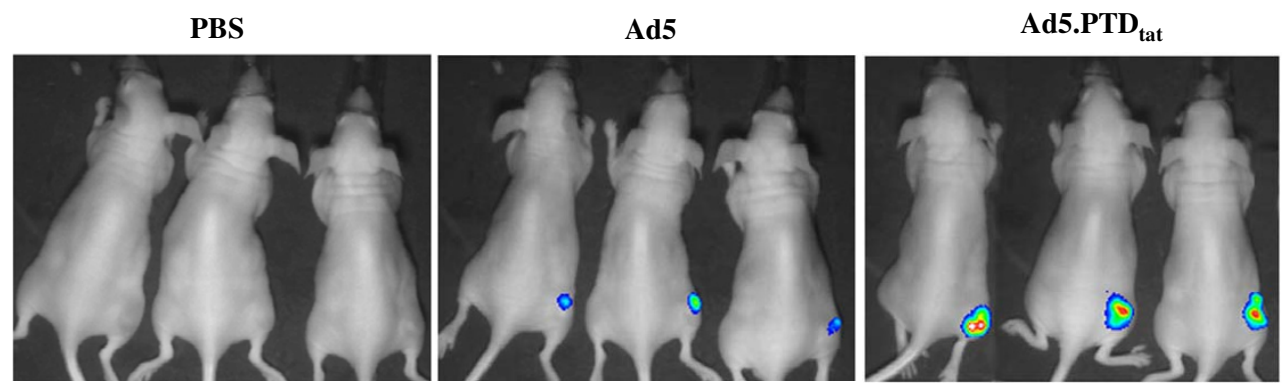

B
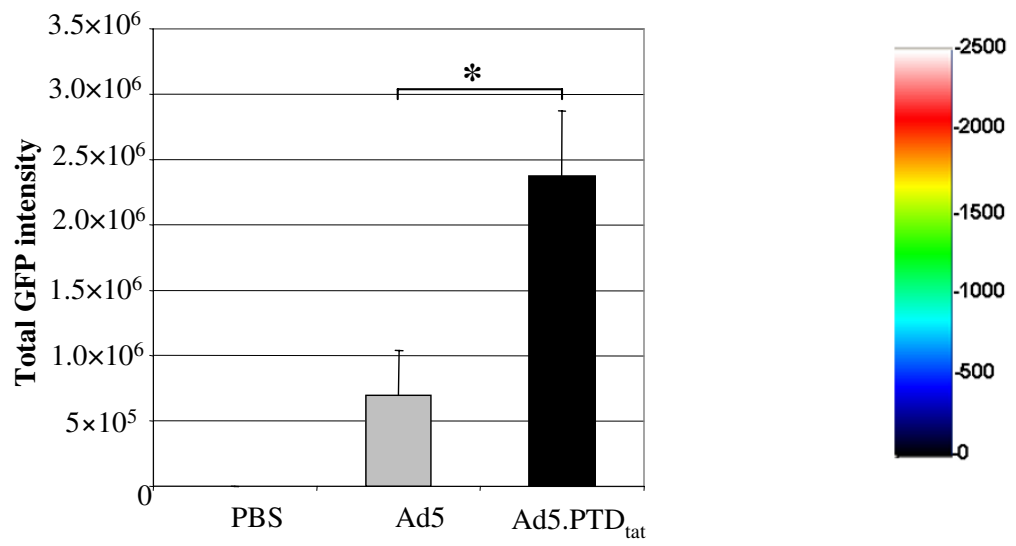

Figure 6

PTD $_{\text {tat }}$ modification of Ad5 fiber enhanced in vivo gene delivery efficacy of the vector. In vivo gene delivery of Ad5.PTD ${ }_{\text {tat }}$ was examined using a non-invasive fluorescence imaging technique in low-CAR expressing tumor models. 1010 VPs of Ad5 or Ad5.PTD ${ }_{\text {tat }}$ were injected into the subcutaneous UI I8MG tumors, and in vivo green fluorescence images were acquired at different days post viral injection. (A) Representative in vivo images from PBS, Ad5, or Ad5.PTD tat injected mouse tumor models at day 7 after vector administration. The colors representing different intensities of signal are shown on the color bar. Ad5.PTD tat infection resulted in more intensive GFP signals than unmodified Ad5 vectors. (B) Quantitative analysis of the GFP intensity in the tumor model of each group. The * marks significant differences $(P<0.0 \mathrm{I})$ as analyzed by the Student's t-test. 
allowed us to visually detect the enhanced gene delivery in vivo.

As a cell penetrating peptide, $\mathrm{PTD}_{\mathrm{tat}}$ is capable of traversing the plasma membrane of mammalian cells. Since the initial description that PTD $_{\text {tat }}$ is responsible for the ability of the HIV Tat protein to enter mammalian cells, PTD $_{\text {tat }}$ has attracted tremendous interest as a drug delivery vehicle [16-20]. Further interest has been stimulated by the observation that PTDs can facilitate systemic delivery of biologically active recombinant proteins in vivo [3235,37 . Since inefficient gene delivery into target cells has been one of the major limitations in Ad5-mediated gene therapy, in this study, we attempted to employ PTD ${ }_{\text {tat }}$ peptide to facilitate Ad5 mediated gene delivery. Employment of PTDs to facilitate virus infection has been investigated previously, but only using non-genetic methods [37,42]. In particular, chemically synthesized PTDs or bi-specific adaptor proteins consisting of PTDs and the extracelluar domain of CAR have been used to coat Ad vectors. These strategies too resulted in enhanced gene delivery $[37,42]$. Compared to the non-genetic methods, our genetically PTD $_{\text {tat }}$ modified vector has major advantages for two major reasons: 1) genetic modification allows stable interaction between Ad5 and the PTD ${ }_{\text {tat }}$ targeting epitope, thus reducing the volatility associated with the affinity and stability of protein-protein interactions in the presence of different environmental factors. This is critical especially for in vivo applications; and 2) genetic modification does not require production of peptides or fusion proteins other than the viral vector, while large amounts of high quality protein/peptide production is required for nongenetic strategies (in addition to high quality production of the viral vectors), which is especially important for in vivo studies.

One issue associated with $\mathrm{PTD}_{\mathrm{tat}}$-mediated protein delivery is the inefficient release of $\mathrm{PTD}_{\mathrm{tat}}$ fusion proteins from the endosomal compartments [24,45-48]. It has been demonstrated that a large proportion of the PTD ${ }_{t a t}$ fusion protein remains trapped in non-cytosolic compartments even though it is efficiently taken up by the cells. This apparently would compromise the therapeutic effect of the fusion protein. In our study, we examined the distribution of Ad5.PTD $D_{\text {tat }}$ particles in cells at various time points (from 0.5 hour to 4 hours) following addition of the viruses to the cells by immunofluorescent staining, and found that the distribution of Ad5.PTD ${ }_{\text {tat }}$ inside the cells was similar to that of unmodified Ad5 vectors (data not shown). This indicates endosomal trapping is not significant, if any present at all, with Ad5.PTD ${ }_{\text {tat }}$ infection of cells. In addition, the enhanced gene delivery mediated by Ad5.PTD ${ }_{\text {tat }}$ confirmed that the virions were able to efficiently escape the endosomal compartment.
The potential utility of the infectivity-enhanced Ad5.PTDtat vector in cancer gene therapy was initially investigated in this study using low-CAR expressing tumor models. Indeed, many tumor cells have been shown to express very low levels of CAR, which is partially responsible for the low efficacy of Ad5 mediated cancer gene therapy in in vivo studies, especially in clinical trials [1-3]. The ability of Ad5.PTD ${ }_{\text {tat }}$ to improve the gene delivery efficacy is attributable to the PTD ${ }_{\text {tat }}$ motif, which binds to the negatively charged motifs expressed on cell surface, in particular, heparan sulfate containing proteoglycans that are widely expressed in a variety of cells including tumor cells [4951]. In addition to cancer gene therapy, Ad5.PTD ${ }_{\text {tat }}$ may also be applied in other gene therapy applications where infectivity-enhancement is beneficial. Infectivityenhanced vectors will not only allow efficient gene delivery into low-CAR target cells, but also allow use of a reduced amount of viral vectors, thus reducing vectorassociated toxicity.

Previous studies have developed several other infectivityenhanced vectors, which include Ad5 vectors modified with RGD, polylysine, or knobs from other Ad serotypes [13-15,52]. Since each of the modified vectors uses a unique extra targeting motif, the enhanced gene delivery efficacy in a specific cell type depends on the expression of individual receptors on its cell surface. Similar to $\mathrm{PTD}_{\text {tat }^{\prime}}$ the polylysine epitope, which is composed of a stretch of lysine residues, is highly basic, and can utilize heparan sulfate as its receptor. Nonetheless, the interaction between PTD $_{\text {tat }}$ and heparan sulfate is not only based on ionic intereactions, but also on the specific structures of the peptide and the proteoglycans [27-29]. Therefore, the choice of an infectivity-enhanced vector needs to be determined for each specific application involving gene delivery enhancement.

\section{Conclusion}

Our data showed that a genetically modified Ad5 vector, Ad5.PTD ${ }_{\text {tat' }}$ maintained the ability to interact with its native receptor CAR, and delivered transgenes into both high-CAR and low-CAR cells more efficiently than the unmodified Ad5 vector. Our data further showed Ad5.PTD ${ }_{\text {tat }}$ infected cells via both CAR and PTD ${ }_{\text {tat }}$ pathways. More significantly, Ad5.PTD ${ }_{\text {tat }}$ exhibited enhanced gene delivery in vivo in a tumor model, and thus may be useful for gene therapy applications involving low gene delivery efficacy.

\section{Methods \\ Cell culture}

The human embryonic kidney 293 cells stably transformed with Ad-E1 DNA, human lung carcinoma A549 cells, human cervix adenocarcinoma Hela cells, human embryonic rhabdomyosarcoma RD cells, and human gli- 
oma D65MG and U118MG cells were all obtained from the American Type Culture Collection (ATCC, Manassas, VA). The 293 cells, A549 cells and U118MG cells were cultured in Dulbecco's modified Eagle's medium/Ham's F12 medium (DMEM/F12) containing 10\% fetal bovine serum (FBS) and $2 \mathrm{mM}$ L-glutamine. Hela cells were cultured cultured in minimum essential Eagle medium (MEM) containing 10\% FBS and $2 \mathrm{mM}$ L-glutamine. Both $\mathrm{RD}$ and D65MG cells were cultured in DMEM containing $10 \% \mathrm{FBS}$ and $2 \mathrm{mM}$ L-glutamine. All of the cells were maintained at $37^{\circ} \mathrm{C}$ in a $5 \% \mathrm{CO}_{2}$ humidified incubator.

\section{Generation of the Ad5.PTD tat $_{\text {vector }}$}

Genetic modification of the Ad5 vector with $\mathrm{PTD}_{\text {tat }}$ was achieved using our previously established fiber modification system [15]. In brief, the fiber shuttle vector containing a unique SnaBI restriction site immediately in front of the stop code of the fiber gene, named pNEB.PK.SnaBI, was used to generate a PTD ${ }_{\text {tat }}$ modification. The sense and antisense oligonucleotides encoding the PTD ${ }_{\text {tat }}$ motif, 5'phos-ACT TTT TCA TAC ATT GCG CAA GAA GGC GGT GGA GGG TAT GGC AGG AAG AAG CGG AGA CAG CGA CGA AGA TAA TAA A-3' (sense) and 5'-phos-TTT ATT ATC TTC GTC GCT GTC TCC GCT TCT TCC TGC CAT ACC CTC CAC CGC CTT CTT GCG CAA TGT ATG AAA AAG T -3' (antisense), were annealed and cloned into the fiber shuttle vector pNEB.PK.SnaBI. This resulted in the fiber modified shuttle vector $\mathrm{PNEB}$.PK.PTD ${ }_{\text {tat. }}$ In order to incorporate the modified fiber into an Ad5 genome, pNEB.PK.PTD tat $_{\text {was }}$ linearized and recombined in Escherichia coli (E. coli) BJ5183 with a linearized Ad5 backbone plasamid pVK50 that contained the CMV promoter driven GFP reporter gene in its $\mathrm{E} 1$ region. After the positive recombinant plasmid, designated pAd5.PTD ${ }_{\text {tat }}$, was identified, stable and high quality plasmid was obtained from E. coli DH5 $\alpha$ after re-transformation of the construct. The modification was confirmed by sequencing analysis.

The modified virus Ad5.PTD tat $_{\text {was rescued and purified as }}$ previously described [53]. In brief, the pAd5.PTD ${ }_{\text {tat }}$ plasmid was digested with PacI (to release the viral genome), purified, and transfected into 293 cells stably expressing the complementary E1 genes. After the virus plaques formed, they were amplified in 293 cells, and purified utilizing a standard $\mathrm{CsCl}$ gradient protocol. The viral particle (VP) titer was determined using a conversion factor of 1.1 $\times 10^{12} \mathrm{VPs} / \mathrm{ml}$ per absorbance unit at $260 \mathrm{~nm}$.

\section{ELISA}

The ELISA binding assay was performed essentially as described [15]. In brief, $10^{9}$ VPs of either Ad5 or Ad5.PTDtat in $100 \mu \mathrm{l}$ of $100 \mathrm{mM}$ carbonate buffer ( $\mathrm{pH}$ 9.5) was immobilized in each well of a 96-well maxisorp plate (Nunc, Roskilde, Denmark) by overnight incubation at $4^{\circ} \mathrm{C}$. Following extensive washes with Tris-buffered saline
(TBS) containing $0.05 \%$ Tween 20 (TBS-Tween), and blocking with $2 \%$ bovine serum albumin (BSA) in TBSTween, the viruses were incubated with varying amounts of purified recombinant sCAR. The binding of sCAR to the viruses was detected by incubation with anti-CAR antibody (Santa Cruz Biotechnology Inc., Santa Cruz, CA), followed by an AP-conjugated secondary antibody incubation. AP activity reflecting the amount of bound sCAR was determined using a color reaction with p-nitrophenyl phosphate (Sigma, St. Louis, MO) as recommended by the manufacturer. The absorbance at $405 \mathrm{~nm}$ (OD405) was obtained using PowerWaveHT 340 microplate reader (BioTek Instruments Inc., Winooski, VT).

\section{Cell binding assay}

Cells were cultured in 6-well plates until they were confluent. The plate was then cooled down on ice, and incubated with Ad5 or Ad5.PTD ${ }_{\text {tat }}$ at an MOI of $5000 \mathrm{VPs} /$ cell for one hour at $4{ }^{\circ} \mathrm{C}$. After washing cells twice with cold phosphate buffered saline (PBS) on ice, the cells were collected by incubation with Versene ( $0.53 \mathrm{mM}$ EDTA). After two more washes with PBS, the cells were lysed and processed to isolate DNA (Qiagen Inc., Valencia, CA). The viral copy number in the DNA samples were obtained by quantitative PCR using primers designed for the E4 region of adenoviral genome. The data were normalized against actin DNA in each sample.

\section{Gene transfer assay}

Gene transfer efficacy of the viral vectors was assessed with the use of GFP reporter. In the assay, cells were plated in 24-well plates with a density of $10^{5}$ cells per well the day before infection. Then the cells were infected with Ad5 or Ad5.PTD ${ }_{\text {tat }}$ at MOIs of 100 or $500 \mathrm{VPs} /$ cell as described previously [53]. Two days later, GFP expression was examined by fluorescence microscopy and quantified by a Synergy HT fluorescence plate reader (BioTek Instruments Inc., Winooski, VT).

\section{Competitive inhibition assays}

Low-CAR U118MG cells or high-CAR A549 cells were plated in 24-well plates at a density of $10^{5}$ cells per well the day before infection. Viruses equivalent to an MOI of $100 \mathrm{VPs} /$ cell were used for each infection. To block cell surface CAR, recombinant knob protein was pre-incubated with cells at a final concentration of $50 \mu \mathrm{g} / \mathrm{ml}$ prior to viral infection [54], and to block the PTD ${ }_{\text {tat }}$ epitope, the viruses were pre-incubated with $100 \mu \mathrm{g} / \mathrm{ml}$ of heparin $[15,54]$. Two hours after infection, the cells were washed with PBS, and refreshed with complete media containing $10 \%$ FBS. The cells were cultured for two days in the humidified $37^{\circ} \mathrm{C}, 5 \% \mathrm{CO}_{2}$ incubator, and GFP microscopy was performed to examine the transgene expression. 


\section{In vivo gene delivery}

The subcutaneous tumors were established in athymic nude mice using $1 \times 10^{7} \mathrm{U} 118 \mathrm{MG}$ cells per tumor per mouse. After the tumors developed to $\sim 0.5 \mathrm{~cm}$ in diameter, PBS or $10^{10}$ VPs of Ad5 or Ad.PTD ${ }_{\text {tat }}$ were injected into each tumor $(n=6)$. GFP expression was analyzed at 3,7 , and 10 days post infection using a custom-built non-invasive optical imaging system described previously [55]. The mice were placed in the imaging chamber under anesthesia with 3\% isoflurane. Green fluorescence images were acquired at $\mathrm{f} / 8$ with 20 -second exposure using a combination of excitation filter HQ487/15× and emission filter D535/30m (Chroma Technology, Rockingham, VT) supported by WinView32 software (Roper Scientific Inc., Trenton, NJ). All of the procedures involving animals were approved by the Institutional Animal Care and Use Committee of the University of Alabama at Birmingham and performed according to their guidelines.

\section{Competing interests}

The author(s) declare that they have no competing interests.

\section{Authors' contributions}

TH participated in the generation and in vitro characterization of the adenoviral vectors. YT carried out in vitro and in vivo gene transfer assays. HU performed immunohistochemistry studies. LEP participated in cell culture and tumor model establishment. GPS helped in immunohistochemical studies and in the preparation of the manuscript. JLC assisted in the design of the study and manuscript preparation. HW conceived of the study, participated in its design and coordination, and drafted the manuscript. All authors read and approved the final manuscript.

\section{Acknowledgements}

The authors thank Dr. Joel N. Glasgow for providing recombinant knob protein and Minghui Wang for assistance in quantitative PCR analysis. This work was supported by the NIH brain SPORE grant P50 CA097247 and the Juvenile Diabetes Research Foundation grants I-2005-7| and 5-2007-660.

\section{References}

I. Glasgow JN, Everts M, Curiel DT: Transductional targeting of adenovirus vectors for gene therapy. Cancer Gene Ther 2006, I3(9):830-844.

2. Hedley SJ, Chen J, Mountz JD, Li J, Curiel DT, Korokhov N, Kovesdi I: Targeted and shielded adenovectors for cancer therapy. Cancer Immunol Immunother 2006, 55(II): |4I2-14 I9.

3. Rein DT, Breidenbach M, Curiel DT: Current developments in adenovirus-based cancer gene therapy. Future Oncol 2006, 2(I):137-143.

4. Bai M, Harfe B, Freimuth P: Mutations that alter an Arg-Gly-Asp (RGD) sequence in the adenovirus type 2 penton base protein abolish its cell-rounding activity and delay virus reproduction in flat cells. J Virol 1993, 67(9):5198-5205.

5. Bergelson JM, Cunningham JA, Droguett G, Kurt-Jones EA, Krithivas A, Hong JS, Horwitz MS, Crowell RL, Finberg RW: Isolation of a common receptor for Coxsackie $B$ viruses and adenoviruses 2 and 5. Science 1997, 275(5304): 1320-1323.
6. Louis N, Fender P, Barge A, Kitts P, Chroboczek J: Cell-binding domain of adenovirus serotype 2 fiber. I Virol 1994, 68(6):4104-4I06.

7. Wickham TJ, Mathias P, Cheresh DA, Nemerow GR: Integrins alpha $v$ beta 3 and alpha $v$ beta 5 promote adenovirus internalization but not virus attachment. Cell 1993, 73(2):309-319.

8. Dmitriev I, Kashentseva E, Rogers BE, Krasnykh V, Curiel DT: Ectodomain of coxsackievirus and adenovirus receptor genetically fused to epidermal growth factor mediates adenovirus targeting to epidermal growth factor receptor-positive cells. J Virol 2000, 74(15):6875-6884.

9. Li HJ, Everts M, Pereboeva L, Komarova S, Idan A, Curiel DT, Herschman HR: Adenovirus tumor targeting and hepatic untargeting by a coxsackie/adenovirus receptor ectodomain anticarcinoembryonic antigen bispecific adapter. Cancer Res 2007, 67( I I):5354-536I.

10. Tang Y, Han T, Everts M, Zhu ZB, Gillespie GY, Curiel DT, Wu H: Directing adenovirus across the blood-brain barrier via melanotransferrin (P97) transcytosis pathway in an in vitro model. Gene Ther 2007, I 4(6):523-532.

II. Watkins SJ, Mesyanzhinov VV, Kurochkina LP, Hawkins RE: The 'adenobody' approach to viral targeting: specific and enhanced adenoviral gene delivery. Gene Ther 1997, 4(10): $1004-1012$

12. Belousova N, Krendelchtchikova V, Curiel DT, Krasnykh V: Modulation of adenovirus vector tropism via incorporation of polypeptide ligands into the fiber protein. I Virol 2002, 76(I7):862I-863I.

13. Dmitriev I, Krasnykh V, Miller CR, Wang M, Kashentseva E, Mikheeva G, Belousova N, Curiel DT: An adenovirus vector with genetically modified fibers demonstrates expanded tropism via utilization of a coxsackievirus and adenovirus receptorindependent cell entry mechanism. J Virol 1998, 72(I 2):9706-97|3.

14. Wickham TJ, Roelvink PW, Brough DE, Kovesdi I: Adenovirus targeted to heparan-containing receptors increases its gene delivery efficiency to multiple cell types. Nat Biotechnol 1996 , I4(II): 1570-1573.

15. Wu H, Seki T, Dmitriev I, Uil T, Kashentseva E, Han T, Curiel DT: Double modification of adenovirus fiber with RGD and polylysine motifs improves coxsackievirus-adenovirus receptorindependent gene transfer efficiency. Hum Gene Ther 2002, I3(13):1647-1653

16. Deshayes S, Morris MC, Divita G, Heitz F: Cell-penetrating peptides: tools for intracellular delivery of therapeutics. Cell Mol Life Sci 2005, 62(16):1839-1849.

17. Fittipaldi A, Giacca M: Transcellular protein transduction using the Tat protein of HIV-I. Adv Drug Deliv Rev 2005, 57(4):597-608.

18. Joliot A, Prochiantz A: Transduction peptides: from technology to physiology. Nat Cell Biol 2004, 6(3): 189-196.

19. Snyder EL, Dowdy SF: Cell penetrating peptides in drug delivery. Pharm Res 2004, 21 (3):389-393.

20. Wadia J, Dowdy SF: Transmembrane delivery of protein and peptide drugs by TAT-mediated transduction in the treatment of cancer. Adv Drug Deliv Rev 2005, 57(4):579-596.

21. Ruben S, Perkins A, Purcell R, Joung K, Sia R, Burghoff R, Haseltine WA, Rosen CA: Structural and functional characterization of human immunodeficiency virus tat protein. J Virol 1989, 63(I): I-8.

22. Vives E, Brodin P, Lebleu B: A truncated HIV-I Tat protein basic domain rapidly translocates through the plasma membrane and accumulates in the cell nucleus. J Biol Chem 1997, 272(25): $16010-16017$.

23. Ferrari A, Pellegrini V, Arcangeli C, Fittipaldi A, Giacca M, Beltram F: Caveolae-mediated internalization of extracellular HIV-I tat fusion proteins visualized in real time. Mol Ther 2003, 8(2):284-294.

24. Fischer R, Kohler K, Fotin-Mleczek M, Brock R: A stepwise dissection of the intracellular fate of cationic cell-penetrating peptides. I Biol Chem 2004, 279( (3): I 2625-12635.

25. Fittipaldi A, Ferrari A, Zoppe M, Arcangeli C, Pellegrini V, Beltram F, Giacca M: Cell membrane lipid rafts mediate caveolar endocytosis of HIV-I Tat fusion proteins. J Biol Chem 2003, 278(36):34|4|-34|49.

26. Richard JP, Melikov K, Vives E, Ramos C, Verbeure B, Gait MJ, Chernomordik LV, Lebleu B: Cell-penetrating peptides. A reevalua- 
tion of the mechanism of cellular uptake. J Biol Chem 2003 278(I):585-590.

27. Tyagi M, Rusnati M, Presta M, Giacca M: Internalization of HIV-I tat requires cell surface heparan sulfate proteoglycans. J Biol Chem 200I, 276(5):3254-326I.

28. Maccarana M, Casu $B$, Lindahl U: Minimal sequence in heparin/ heparan sulfate required for binding of basic fibroblast growth factor. J Biol Chem 1993, 268(32):23898-23905.

29. Rusnati M, Tulipano G, Spillmann D, Tanghetti E, Oreste P, Zoppetti G, Giacca M, Presta M: Multiple interactions of HIV-I Tat protein with size-defined heparin oligosaccharides. I Biol Chem 1999, 274(40):28| 98-28205.

30. Spillmann D, Witt D, Lindahl U: Defining the interleukin-8-binding domain of heparan sulfate. J Biol Chem 1998, 273(25): I5487-I5493.

31. Nagahara H, Vocero-Akbani AM, Snyder EL, Ho A, Latham DG, Lissy NA, Becker-Hapak M, Ezhevsky SA, Dowdy SF: Transduction of full-length TAT fusion proteins into mammalian cells: TAT. p27Kipl induces cell migration. Nat Med 1998, 4(I 2): 1449-1452.

32. Asoh S, Ohsawa I, Mori T, Katsura K, Hiraide T, Katayama Y, Kimura M, Ozaki D, Yamagata K, Ohta S: Protection against ischemic brain injury by protein therapeutics. Proc Natl Acad Sci U S A 2002, 99(26): $17107-17 \mid 12$

33. Cao G, Pei W, Ge H, Liang Q, Luo Y, Sharp FR, Lu A, Ran R, Graham $\mathrm{SH}$, Chen J: In Vivo Delivery of a Bcl-xL Fusion Protein Containing the TAT Protein Transduction Domain Protects against Ischemic Brain Injury and Neuronal Apoptosis. J Neurosci 2002, 22(I 3):5423-543 |

34. Orii KO, Grubb JH, Vogler C, Levy B, Tan Y, Markova K, Davidson BL, Mao O, Orii T, Kondo N, Sly WS: Defining the pathway for Tat-mediated delivery of beta-glucuronidase in cultured cells and MPS VII mice. Mol Ther 2005, I 2(2):345-352

35. Schwarze SR, Ho A, Vocero-Akbani A, Dowdy SF: In vivo protein transduction: delivery of a biologically active protein into the mouse. Science 1999, 285(5433): I569-1572.

36. Eguchi A, Akuta T, Okuyama H, Senda T, Yokoi H, Inokuchi H, Fujita S, Hayakawa T, Takeda K, Hasegawa M, Nakanishi M: Protein transduction domain of HIV-I Tat protein promotes efficient delivery of DNA into mammalian cells. J Biol Chem 200I, 276(28):26204-26210.

37. Gratton JP, Yu J, Griffith JW, Babbitt RW, Scotland RS, Hickey R, Giordano FJ, Sessa WC: Cell-permeable peptides improve cellular uptake and therapeutic gene delivery of replicationdeficient viruses in cells and in vivo. Nat Med 2003, 9(3):357-362.

38. Ignatovich IA, Dizhe EB, Pavlotskaya AV, Akifiev BN, Burov SV, Orlov SV, Perevozchikov AP: Complexes of plasmid DNA with basic domain 47-57 of the HIV-I Tat protein are transferred to mammalian cells by endocytosis-mediated pathways. J Biol Chem 2003, 278(43):42625-42636.

39. Lewin M, Carlesso N, Tung CH, Tang XW, Cory D, Scadden DT, Weissleder R: Tat peptide-derivatized magnetic nanoparticles allow in vivo tracking and recovery of progenitor cells. Nat Biotechnol 2000, 18(4):410-4I4.

40. Sandgren S, Cheng F, Belting M: Nuclear targeting of macromolecular polyanions by an HIV-Tat derived peptide. Role for cell-surface proteoglycans. J Biol Chem 2002, 277(4 I ):38877-38883.

4I. Torchilin VP, Rammohan R, Weissig V, Levchenko TS: TAT peptide on the surface of liposomes affords their efficient intracellular delivery even at low temperature and in the presence of metabolic inhibitors. Proc Natl Acad Sci U S A 200I, 98(I 5):8786-879|.

42. Kuhnel F, Schulte B, Wirth T, Woller N, Schafers S, Zender L, Manns $M$, Kubicka S: Protein transduction domains fused to virus receptors improve cellular virus uptake and enhance oncolysis by tumor-specific replicating vectors. J Virol 2004, 78(24): $13743-13754$.

43. Seki T, Dmitriev I, Suzuki K, Kashentseva E, Takayama K, Rots M, Uil $\mathrm{T}, \mathrm{Wu} \mathrm{H}$, Wang M, Curiel DT: Fiber shaft extension in combination with $\mathrm{HI}$ loop ligands augments infectivity for CAR-negative tumor targets but does not enhance hepatotropism in vivo. Gene Ther 2002, 9(16): I I0I-1 I08

44. Van Houdt WJ, Wu H, Glasgow JN, Lamfers ML, Dirven CM, Gillespie GY, Curiel DT, Haviv YS: Gene delivery into malignant glioma by infectivity-enhanced adenovirus: in vivo versus in vitro models. Neuro Oncol 2007, 9(3):280-290.

45. Albarran B, To R, Stayton PS: A TAT-streptavidin fusion protein directs uptake of biotinylated cargo into mammalian cells. Protein Eng Des Sel 2005, 18(3): | 147-152.

46. Al-Taei S, Penning NA, Simpson JC, Futaki S, Takeuchi T, Nakase I, Jones AT: Intracellular traffic and fate of protein transduction domains HIV-I TAT peptide and octaarginine. Implications for their utilization as drug delivery vectors. Bioconjug Chem 2006, I ( (I):90-100.

47. Loison F, Nizard P, Sourisseau T, Le Goff P, Debure L, Le Drean Y, Michel D: A ubiquitin-based assay for the cytosolic uptake of protein transduction domains. Mol Ther 2005, I I(2):205-2I4.

48. Wadia JS, Stan RV, Dowdy SF: Transducible TAT-HA fusogenic peptide enhances escape of TAT-fusion proteins after lipid raft macropinocytosis. Nat Med 2004, 10(3):310-3।5.

49. Blackhall FH, Merry CL, Davies EJ, Jayson GC: Heparan sulfate proteoglycans and cancer. $\mathrm{Br} /$ Cancer 200I, 85(8): $1094-1098$.

50. Davies EJ, Blackhall FH, Shanks JH, David G, McGown AT, Swindell R, Slade RJ, Martin-Hirsch P, Gallagher JT, Jayson GC: Distribution and clinical significance of heparan sulfate proteoglycans in ovarian cancer. Clin Cancer Res 2004, I (1 5):5 178-5I86.

5I. Steck PA, Moser RP, Bruner JM, Liang L, Freidman AN, Hwang TL, Yung WK: Altered expression and distribution of heparan sulfate proteoglycans in human gliomas. Cancer Res 1989, 49(8):2096-2103.

52. Kanerva A, Mikheeva GV, Krasnykh V, Coolidge CJ, Lam JT, Mahasreshti PJ, Barker SD, Straughn M, Barnes MN, Alvarez RD, Hemminki A, Curiel DT: Targeting adenovirus to the serotype 3 receptor increases gene transfer efficiency to ovarian cancer cells. Clin Cancer Res 2002, 8(I):275-280.

53. Wu H, Dmitriev I, Kashentseva E, Seki T, Wang M, Curiel DT: Construction and characterization of adenovirus serotype 5 packaged by serotype 3 hexon. I Virol 2002, 76(24): $12775-12782$

54. Glasgow JN, Kremer EJ, Hemminki A, Siegal GP, Douglas JT, Curiel DT: An adenovirus vector with a chimeric fiber derived from canine adenovirus type 2 displays novel tropism. Virology 2004 , 324(I): $103-116$

55. Le LP, Le HN, Dmitriev IP, Davydova JG, Gavrikova T, Yamamoto S, Curiel DT, Yamamoto M: Dynamic monitoring of oncolytic adenovirus in vivo by genetic capsid labeling. I Natl Cancer Inst 2006, 98(3):203-2। 4
Publish with Bio Med Central and every scientist can read your work free of charge

"BioMed Central will be the most significant development for disseminating the results of biomedical research in our lifetime. "

Sir Paul Nurse, Cancer Research UK

Your research papers will be:

- available free of charge to the entire biomedical community

- peer reviewed and published immediately upon acceptance

- cited in PubMed and archived on PubMed Central

- yours - you keep the copyright
BioMedcentral 